\title{
Reaching 95\%: decision support tools are the surest way to improve diagnosis now
}

\author{
Mark L Graber
}

Healthcare Quality and Outcomes, RTI International, St James, NY, USA

\section{Correspondence to} Dr Mark L Graber, Healthcare Quality and Outcomes, RTI International, St James, NY 11780, USA graber.mark@gmail.com

Accepted 25 September 2021

\section{SLinked}

- http://dx.doi.org/10.1136/ bmjqs-2021-013493

\section{Check for updates}

(C) Author(s) (or their employer(s)) 2021. No commercial re-use. See rights and permissions. Published by BMJ.

To cite: Graber ML. BMJ Qual Saf Epub ahead of print: [please include Day Month Year]. doi:10.1136/ bmjqs-2021-014033
Rory Staunton, a 12 year-old boy, presented with fever, vomiting and mottled skin. Was this gastroenteritis?

Thomas Duncan's symptoms were headache, dizziness, nausea, abdominal pain and fever after recent travel from West Africa. Was this sinusitis?

These two classic cases of diagnostic error beg the question of why the correct diagnosis was missed, and in his classic paper, George Bordage provided a very plausible answer: 'I just didn't think of it." ${ }^{1}$ That is where clinical decision support tools for diagnosis (CDS-Dx), the so-called 'symptom checkers', come in. They work, and would likely have helped the clinicians consider the correct diagnosis in these cases: Rory Staunton's streptococcal sepsis ${ }^{2}$ or Thomas Duncan's Ebola infection, ${ }^{3}$ both of which had a fatal outcome.

\section{CDS-DX WORK}

The report by Sibbald et al published in this issue of BMJ Quality \& Safety adds to the growing evidence that decision support can improve the diagnostic process. ${ }^{4}$ This study was conducted at six different schools, and asked trainees and staff in internal medicine or emergency medicine to diagnose a series of challenging cases using the 'Isabel' CDS-Dx platform either early (right after the chief complaint) or later (after reviewing all of the relevant clinical information) in the diagnostic process. Students and residents included more diseases in their consideration with early use of the 'Isabel' CDS-Dx platform, a finding that could be important in improving diagnosis education. The most dramatic finding in the study was that later use, which is likely how it will be used in practice, improved the likelihood that the correct diagnosis would be included in the differential by
$8 \%$. Moreover, physicians said that using the software was easy and relatively fast.

To put this result in context, the incidence of diagnostic error in primary care practice is roughly $10 \%$; we get it right only $90 \%$ of the time. Even a $5 \%$ improvement, which would elevate us to $95 \%$, would eliminate half of the harm associated with diagnostic error, thought to be the most serious safety concern in the USA today.

Diagnosis is likely the most complex cognitive tasks that humans face. There are, roughly, only 200 symptoms but over 10,000 diseases, and each disease may present in different ways, depending on the patient. Standard textbooks of medicine cover less than 1000 of these, and often describe just classic presentations. The current generation of CDS-Dx systems, including Isabel, cover thousands more, and CDS-Dx platforms that specialise in rare diseases are emerging. ${ }^{5}$ Rare diseases will affect roughly 6\% of the population at some point in their lifetime, with conditions that most clinicians will have never seen, or even heard of. Another unique resource for diagnosis is the VisualDx CDS-Dx system, which includes over 45000 images, as especially helpful resource for conditions with visible manifestations. These include the variable presentations of common entities, for example, how the same rash might appear in patients with different skin colour.

The positive results seen by Sibbald et al are no aberration. Just as examples, a study in family medicine found that use of DXplain for decision support improved diagnostic accuracy by $8 \%$ in simulated cases. ${ }^{6}$ Similarly, Kostopoulou et al reported an 8\% absolute improvement in diagnostic accuracy in diagnosing a series of adult cases using a homegrown 
CDS-Dx resource. ${ }^{7}$ An important finding in this latter study was that using decision support did not lead to excessive testing or consultation, a logical concern whenever you start to consider a larger range of possible diagnoses. The AHRQ SAFER III systematic review analysed 31 published studies and concluded that CDS-Dx improved diagnosis, ${ }^{8}$ as did a separate review from the Margolis Center: CDS-Dx 'has the potential to augment clinicians' intelligence, support their decision-making processes, help them arrive at the correct diagnosis faster, reduce unnecessary testing and treatments otherwise resulting from misdiagnosis, and reduce pain and suffering by starting treatments earlier." At a minimum, reviewing CDS-Dx suggestions ensures that 'System 2', the deliberate, conscious consideration of the diagnostic possibilities, will be available to complement our intuition.

CDS-Dx tools are not perfect by a long shot. The diagnostic recommendations will vary considerably depending on what key findings are entered, and the list of possibilities is long. This can be overwhelming for novices, but experienced physicians excel at sorting these out. And not all CDS-Dx products are created equal; substantial performance differences have been noted in comparative studies. ${ }^{10} \mathrm{~A}$ frequent criticism of CDS-Dx research studies is that they typically ask physicians to evaluate written case scenarios, a far cry from the world of real patients. The study of Kostopoulou et al described above addressed this by using standardised patients in real practice settings. ${ }^{7}$ Similarly, using Isabel in diagnosing admissions to a paediatric intensive care unit increased the correct diagnosis from $89 \%$ to $92 \%{ }^{11}$

\section{WHY IS CDS-DX UNDERUSED?}

Especially in view of their potential to improve diagnosis, usage of CDS-Dx systems to date is underwhelming. ${ }^{12}$ Even when they are available, clinicians most often do not consult them. Several factors may be in play (figure 1). The case for improving diagnosis has not reached the front lines. Most clinicians believe they are doing just fine, and do not appreciate the magnitude of the diagnostic error problem, or that they are susceptible to it. This is where quality assurance and performance improvement efforts could make a real difference, by providing the appropriate motivation to recognise and address diagnostic error as a major patient safety concern. The problem is not the technology, it lies in motivating users to take advantage of it. Even when they are aware of the general problem of diagnostic error, many clinicians believe they personally do not need any help, especially for cases which seem straightforward. Unfortunately, cases that seem simple end up compromising the bulk of cases involving diagnostic error; overconfidence is ubiquitous in diagnostic practice, and calibration is poor-clinicians do not do well in predicting whether their diagnosis is right or wrong. ${ }^{13}$

Also, the ever-increasing pressure to increase clinical production creates an incentive to skip an extra step, like checking the recommendations from a CDS-Dx system. In his classic study of why CDS products in general are underused, Sittig et al found that $80 \%$ of clinicians said they were less likely to use CDS advice if they were behind schedule, and $84 \%$ said they were behind schedule some, most or all of the time. ${ }^{14}$

\section{THE FUTURE OF CDS-DX}

There are three promising trends regarding the uptake and potential use of CDS-Dx systems:

First, never mind that clinicians are reluctant; patients are eager users of CDS-Dx tools. A variety of patient-facing versions are now available and usage is increasing impressively. As an example, patients can access a version of the Isabel CDS-Dx system customised for their use, and it provides triage advice in addition to diagnostic suggestions. ${ }^{15}$ All told, over 50 patient-facing apps that aim to improve diagnosis are findable on the internet, ${ }^{16}$ and according to surveys, patients like these tools. ${ }^{17}$ Patients will not be as adept as clinicians in deriving appropriate diagnostic considerations, but having patients offer up these alternatives to their physicians may prove to be an effective way to prevent the many diagnostic errors that result from

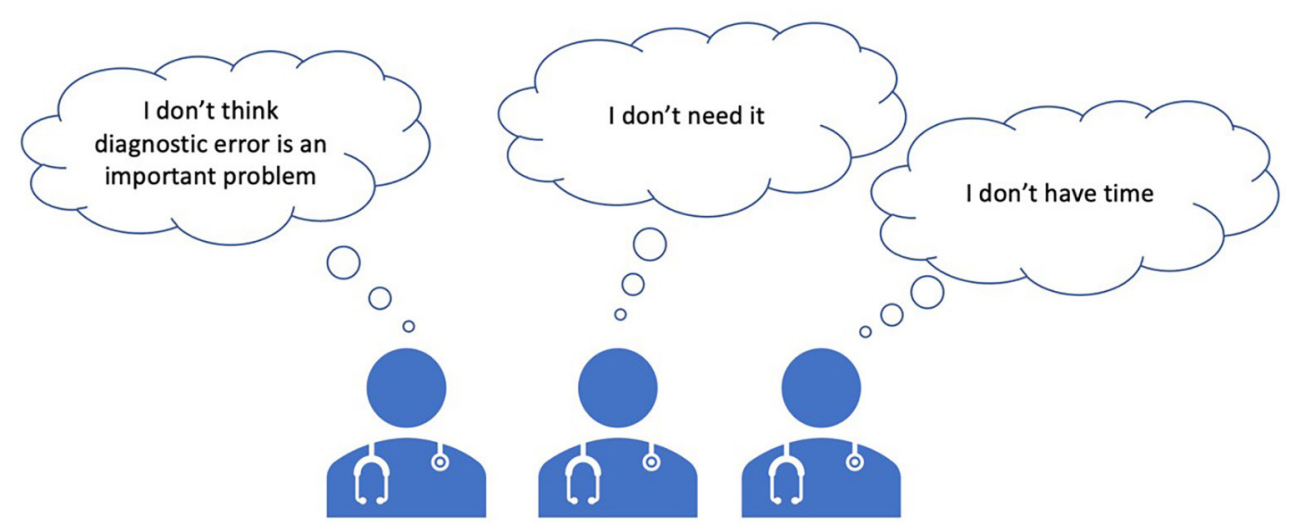

Figure 1 Key reasons clinical decision support for diagnosis is underused. 
premature closure and simply accepting the first possibility that comes to mind, assuming that their physicians are receptive and listening.

Second, knowledge resources are improving in parallel. In contrast to the spotty uptake and use of CDS-Dx systems, decision support resources that directly access medical knowledge content are widely deployed, and can independently help improve diagnosis. ${ }^{18}$ UptoDate, perhaps the most widely used content-focused CDS product, has been shown to improve diagnosis, ${ }^{19}$ and similarly positive results were seen when clinicians used a CDS system linked to BMJ Best Practice. ${ }^{20}$ It is reasonable to hope that as physicians acquire familiarity with using contentfocused CDS systems, this may translate to increased acceptance and use of the CDS-Dx products that specialise in optimising differential diagnosis. Future products that marry the two may be the ideal answer.

Third, using decision support tools is becoming faster and easier. Consulting a CDS-Dx product inserts an additional, somewhat disruptive step in clinical workflow. ${ }^{21}$ Listening to the needs and wants of clinical users, ${ }^{22}$ and considering the human factors issues involved, ${ }^{23}$ can help optimise how often and how effectively these resources will be used. The next steps in the evolution of CDS-Dx, where these systems become well integrated in the electronic health record, will be especially important. Next-generation systems, based on machine learning and artificial intelligence, will scour the clinical notes to suggest diseases that should not be missed, and 'push out' diagnostic suggestions instead of our having to pull them. ${ }^{2425}$

\section{CONCLUSION}

Diagnostic errors are the number one patient safety concern in healthcare today, inflicting harm on hundreds of thousands of patients in the USA annually. The problem is complex and involves the difficulties inherent in diagnosis generally, the known weaknesses of human cognition and the myriad breakdown points in our healthcare systems. There is no one solution to the problem, but of all the proposed interventions to date, the case for promoting the use of decision support for diagnosis is strong. These systems are powerful, they are improving all the time, they are ready for use, they are simple and practical to use, and they work.

Right now, clinicians get the diagnosis right $90 \%$ of the time. How can we reach 95\%? CDS-Dx is the best answer: healthcare organisations should make CDS-Dx advice available, and clinicians should consider this advice, and not just for the most difficult cases, for all cases.

Funding The authors have not declared a specific grant for this research from any funding agency in the public, commercial or not-for-profit sectors.

Competing interests None declared.

Patient consent for publication Not required.
Provenance and peer review Commissioned; internally peer reviewed.

\section{REFERENCES}

1 Bordage G. Why did I miss the diagnosis? Some cognitive explanations and educational implications. Acad Med 1999;74:S138-43.

2 Dwyer J. An infection, unnoticed, turns unstoppable. NY Times, 2012. Available: http://www.nytimes.com/2012/07/12/ nyregion/in-rory-stauntons-fight-for-his-life-signs-that-wentunheeded.html? pagewanted $=3 \& \mathrm{x}_{-} \mathrm{r}=2 \& \mathrm{hp}$

3 Upadhyay DK, Sittig DF, Singh H. Ebola US patient zero: lessons on misdiagnosis and effective use of electronic health records. Diagnosis 2014;1:283-7.

4 Sibbald M. Should electronic differential diagnosis support be used early or late in the diagnostic process? A multi-center experimental study of ISABEL. BMJ Qual Saf 2021.

5 Ronicke S, Hirsch MC, Türk E, et al. Can a decision support system accelerate rare disease diagnosis? Evaluating the potential impact of Ada DX in a retrospective study. Orphanet J Rare Dis 2019;14:69.

6 Martinez-Franco AI, Sanchez-Mendiola M, Mazon-Ramirez JJ, et al. Diagnostic accuracy in family medicine residents using a clinical decision support system (DXplain): a randomizedcontrolled trial. Diagnosis 2018;5:71-6.

7 Kostopoulou O, Porat T, Corrigan D, et al. Diagnostic accuracy of GPs when using an early-intervention decision support system: a high-fidelity simulation. Br J Gen Pract 2017;67:e201-8.

8 Hall K, Shoemaker-Hunt S, Hoffman L. Making healthcare safer III: a critical analysis of existing and emerging patient safety practices. Rockville, MD: Agency for Healthcare Research and Quality, 2020.

9 Daniel G, Sharma I, Silcox C, et al. Current state and nearterm priorities for AI-Enabled diagnostic support software in health care. Duke Margolis Center for Health Policy, 2019.

10 Riches N, Panagioti M, Alam R, et al. The effectiveness of electronic differential diagnoses (DDX) generators: a systematic review and meta-analysis. PLoS One 2016;11:e0148991.

11 Thomas NJ, Ramnarayan P, Bell MJ, et al. An international assessment of a web-based diagnostic tool in critically ill children. Technol Health Care 2008;16:103-10.

12 Cheraghi-Sohi S, Alam R, Hann M, et al. Assessing the utility of a differential diagnostic generator in UK general practice: a feasibility study. Diagnosis 2021;8:91-9.

13 Berner ES, Graber ML. Overconfidence as a cause of diagnostic error in medicine. Am J Med 2008;121:S2-23.

14 Sittig DF, Krall MA, Dykstra RH, et al. A survey of factors affecting clinician acceptance of clinical decision support. BMC Med Inform Decis Mak 2006;6:6.

15 Isabel Medical Charity. Enabling patient engagement with a symptom Checker, 2018. Available: https:// infoisabelhealthcarecom/blog/how-symptom-checkers-helpimprove-patient-engagement-download-our-new-white-paper

16 Jutel A, Lupton D. Digitizing diagnosis: a review of mobile applications in the diagnostic process. Diagnosis 2015;2:89-96.

17 Meyer AND, Giardina TD, Spitzmueller C, et al. Patient perspectives on the usefulness of an artificial IntelligenceAssisted symptom Checker: cross-sectional survey study. J Med Internet Res 2020;22:e14679. 


\section{Editorial}

18 Maggio LA, Aakre CA, Del Fiol G, et al. Impact of clinicians' use of electronic knowledge resources on clinical and learning outcomes: systematic review and meta-analysis. J Med Internet Res 2019;21:e13315.

19 Shimizu T, Nemoto T, Tokuda Y. Effectiveness of a clinical knowledge support system for reducing diagnostic errors in outpatient care in Japan: a retrospective study. Int J Med Inform 2018;109:1-4.

20 Tao L, Zhang C, Zeng L, et al. Accuracy and Effects of Clinical Decision Support Systems Integrated With BMJ Best PracticeAided Diagnosis: Interrupted Time Series Study. JMIR Med Inform 2020;8:e16912.

21 Porat T, Delaney B, Kostopoulou O. The impact of a diagnostic decision support system on the consultation: perceptions of GPs and patients. BMC Med Inform Decis Mak 2017;17:79.
22 McParland CR, Cooper MA, Johnston B. Differential diagnosis decision support systems in primary and outof-hours care: a qualitative analysis of the needs of key stakeholders in Scotland. J Prim Care Community Health 2019;10:215013271982931-6.

23 Carayon P, Hoonakker P, Hundt AS, et al. Application of human factors to improve usability of clinical decision support for diagnostic decision-making: a scenario-based simulation study. BMJ Qual Saf 2020;29:329-40.

24 Feldman MJ, Hoffer EP, Barnett GO, et al. Presence of key findings in the medical record prior to a documented high-risk diagnosis. J Am Med Inform Assoc 2012;19:591-6.

25 Richens JG, Lee CM, Johri S, Saurabh J. Improving the accuracy of medical diagnosis with causal machine learning. Nat Commun 2020;11:3923. 